\title{
Designing for cooperation at a Radio Station
}

\author{
Kensing, F.; Simonsen, Jesper; Bødker, Keld
}

Published in:

Proceedings of the Fifth European Conference on Computer-Supported Cooperative Work

\section{Publication date:}

1997

\section{Document Version}

Early version, also known as pre-print

Citation for published version (APA):

Kensing, F., Simonsen, J., \& Bødker, K. (1997). Designing for cooperation at a Radio Station. In W. Prinz, J. A. Hughes, K. Schmidt, \& T. Rodden (Eds.), Proceedings of the Fifth European Conference on ComputerSupported Cooperative Work (pp. 329-344). Kluwer Academic Publishers.

\section{General rights}

Copyright and moral rights for the publications made accessible in the public portal are retained by the authors and/or other copyright owners and it is a condition of accessing publications that users recognise and abide by the legal requirements associated with these rights.

- Users may download and print one copy of any publication from the public portal for the purpose of private study or research.

- You may not further distribute the material or use it for any profit-making activity or commercial gain.

- You may freely distribute the URL identifying the publication in the public portal.

\section{Take down policy}

If you believe that this document breaches copyright please contact rucforsk@kb.dk providing details, and we will remove access to the work immediately and investigate your claim. 


\section{PREPRINT:}

Kensing, F., J. Simonsen, and K. Bødker (1997): "Designing for Cooperation at a Radio Station", in J. Hughes, J., W. Prinz, T. Rodden, and K. Schmidt, (Eds.): Proceedings of the Fifth European Conference on Computer Supported Cooperative Work, Lancaster University, UK, 7-11 September 1997, Kluwer Academic Publishers, pp. 329-344.

\section{Designing for Cooperation at a Radio Station}

Finn Kensing, Jesper Simonsen, and Keld Bødker

Dept. of Computer Science, Roskilde University

Building 20.2, P.O. Box 260, DK 4000 Roskilde, Denmark

Phone: +4546757711

Fax: +45 46754201

Email: $\{$ kensing, simonsen, keldb\}@ruc.dk 


\title{
Designing for Cooperation at a Radio Station
}

\author{
Finn Kensing, Jesper Simonsen, and Keld Bødker \\ Dept. of Computer Science, Roskilde University, Denmark \\ $\{$ kensing, simonsen, keldb\}@ruc.dk
}

\begin{abstract}
We address computer support for work and its coordination in one of the radio channels of the Danish Broadcasting Corporation. Based upon ethnographically inspired analysis and participatory design techniques, we propose design solutions now implemented or under implementation. We focus on cooperative aspects within and among the radio channel's editorial units, and between editorial units and the editorial board. Finally, we discuss technical and organisational aspects of the design, seen in light of recent CSCW concepts.
\end{abstract}

\section{Introduction}

Design of CSCW-systems can be related to at least two different design contexts. When a software company develops a CSCW product for a large market, "product development" (Grudin, 1991), the product will be used in and among various user-groups within an organisation, and/or between different organisations. When we design within an organisation, "in-house development" or "contract development" (Grudin, 1991), we benefit from thinking about the design and the use of the system in terms of specific cooperating ensembles of users (Schmidt and Bannon, 1992). This is what we aim for in this paper.

We use the term "design" in the same way as architects do - focusing on the analysis of needs and opportunities, and the preliminary design of functionality and form. Therefore we see results of a design project to include a conceptual design in terms of a written document, sketches, mock ups and/or prototypes. Also we consider an evaluation of consequences of implementing the design, as well as a plan for the implementation, to be parts of the result. Based upon a design proposal, it should be possible for the organisation to proceed in purchasing and/or developing the proposed design. 
We describe a design project from one of the radio channels in the Danish Broadcasting Corporation, DBC. The project took place in 1995, and the objective was to design a coherent vision of computer support for the planning, production, broadcasting, and administrative follow up of radio programs. A majority of the proposed design is now implemented. For some design proposals however, a final decision was not reached, but was left until during and/or after experiments and negotiations were made during implementation. We used the MUST method, which we have developed over the last six years (Kensing et al., 1996). The method is inspired by ethnographic approaches (see e.g. Hughes et al., 1992; Blomberg et al.,1993) and by participatory design approaches (see e.g. Greenbaum and Kyng, 1991; Muller and Kuhn, 1993) and it aims at combining these approaches (like e.g. Kensing and Winograd, 1991; Hughes et al., 1993; Blomberg et al., 1996; Mogensen and Shapiro, 1996).

Previous studies of CSCW-systems in use have dealt with organisational issues (see e.g. Bullen \& Bennett 1990; Orlikowski, 1992; Okamura et al., 1994; Ackerman, 1994; Rogers, 1994). In most cases the product development oriented CSCW contributions have not taken organisational issues into account. Our design project demonstrates how technical and organisational issues can be dealt with by combining ethnographically inspired analysis and participatory design. Thus it adds to the, according to Plowman et al. (1995), small body of papers describing workplace studies and specific design guidelines. The project's design report addresses technical and organisational issues, and it evaluates the consequences for the various cooperating ensembles of users. This was discussed as part of the channel's evaluation of the report.

When we strive to understand the problems and needs for computer support and elicit requirements in an organisation, we become engaged in a complex situation where various cooperative ensembles of users may or may not share like problems and potential solutions. In this paper we consider two types of such cooperative ensembles within the Danish Broadcasting Corporation's Channel 3. Editorial units are comprised of journalists, technicians, and administrative staff responsible for a daily or weekly program. The editorial board comprises managers at different levels, with different backgrounds, who have a formal meeting once a week to do overall planning. The editorial units and the editorial board represent multiple, different, and reconfigurable groups, which have conflicting interests (in some cases) and which also have to work together in an remarkably dynamic way to produce 24 hours of constant radio programming. How the editorial units and the editorial board are maintained, and how management exerts its ideas for contents in the various programs are both interesting questions to consider. In such a context, artefacts take on a crucial role in facilitating the cooperation. In the paper we focus explicitly on coordination mechanisms within and among editorial units and between editorial units and the editorial board. We relate our experiences to recent concepts developed in the 
CSCW-community, regarding coordination and computational coordination mechanisms.

We present our analysis of work practices at the channel, which is followed by a presentation of the proposed design. The paper is concluded by a discussion of technical as well as organisational aspects of the suggested computational coordination mechanisms in the light of the entire design.

\section{Analysis of Needs for Computer Support}

The structure of DBC is briefly described first, including some recent management initiatives. Then one of the radio channels, Channel 3, is described. Finally we focus, in greater detail, on one of this channel's editorial units, Station $\mathrm{X}$, responsible for a daily radio program.

A design team was comprised of the authors, two internal IT-consultants, and three user representatives. A steering committee was comprised of the chairman of the editorial board, two staff members, and the IT manager. The design team was responsible for the investigation of IT-support for Channel 3.

The analysis below of the organisation and its needs for computer support are a result of applying tools and techniques suggested by the MUST method. For a more detailed analysis see (Kensing et al., forthcoming). The analytic activities were comprised of observation of the planning, production, broadcasting and administrative follow up of radio programs, as well as of management meetings and of the work of several employees on staff; interviews which were recorded, partly transcribed and corrected by the interviewed persons; document analysis of the corporation's strategic reports, and of material used for research, production, broadcasting, and administrative purposes; thinking aloud experiments where employees were asked to describe what they were doing while working; drawing rich pictures of current work practices; analysis of existing software; and information modelling for the purpose of prototyping and time/cost estimates.

These analytic activities were conducted by the design team and approximately one third of the total 140 employees from Channel 3 were involved. They allowed the design team to develop a common understanding of current work practices and to locate potential areas for computer support and/or organisational changes, and to relate these to management strategies. E.g. a lot of rewriting of information took place in various media, the distribution of information among the channel's employees was cumbersome, and the coordination within and among editorial units often failed or was considered confusing and full of disturbances. Concrete design ideas also started to emerge during the above listed activities with users and during the design teams subsequent analyses of the material, e.g. ideas for computer support for the producers' planning of programs, for journalists' research purposes, and for automatic reports for the editorial board as well as for each of the editorial units. 


\section{The Danish Broadcasting Corporation}

DBC is a public, national station founded in the twenties. Since the eighties it has been running as a limited company for which, by law, every radio and TV-set owner has to pay a license fee. DBC produces and broadcasts TV and radio. The radio station consists of three national radio channels, one news group, and nine regional channels.

The following management initiatives had recently taken place or were under implementation when we started. Our design had to take these initiatives into account.

- Layoffs, expanding the hours of broadcasting, computerised selection of music titles and computerised broadcasting from midnight to 6 A.M.

- The editorial board of Channel 3 wants to shift from "after broadcasting monitoring" to a "forward planning process."

- Self steering groups and integration/loosening up professional demarcations.

- A channel should be perceived as a whole by the listeners, rather than as a collection of individual programs.

- Workgroup computing, and as little in-house development as possible.

- From analogue to digital technology for production and broadcasting.

Before the design project started, the unions had already been forced - by layoffs and by management hiring younger, less specialised employees - to accept these initiatives. It was clear that the project should be seen as part of implementing the initiatives, and the employees accepted these premises of the project.

\section{Channel 3 - A Radio Channel}

At Channel 3, 140 journalists, technicians, administrative staff and managers are involved in the production, broadcasting, and administration of 24 hours of radio programming each day all year. The profile of the channel, which broadcasts nation wide, is a mix of music and features for a young or young-minded audience. The channel cooperates with the station's news group that also serves other channels. Channel 3 is organised around some 25 editorial units ( 1 to 15 people), an editorial board, a couple of staff units and an administrative staff, all under the management of a chief editor. An editorial unit - comprised of journalists (some of which are freelancers), technicians and administrative staff is responsible for a radio program that is broadcasted on a daily or weekly basis. Each unit had only very little computer support: a few PC's and terminals to access a wide range of mainframe systems and news agencies.

Each radio program has its own concept, but when e.g. a new CD is released, or during larger political, sport, and musical events, competition may take place between editorial units, though the editorial board tries to coordinate it. Cooperation in terms of discussions of various angles on stories, including 
advertisements and referring to each others programs is encouraged by management and happens on a regular basis.

Our design project focused on activities related to the production, broadcasting and administration of radio programs, rather than on managerial and general administrative work. This is why the work of one of the editorial units will be described in greater detail below. Of course we noticed many differences between editorial units, some of which relate to their needs for IT-support. This will be touched upon in the conclusion, and not dealt with in the description below.

\section{Station X - A Radio Program}

Station $\mathrm{X}$ is a program than runs Monday through Thursday from 4 P.M. to 6.30 P.M. It is staffed by two producers, two hosts, and four reporters. As a consequence of the integration policy, two technicians and two assistants are part of the editorial unit too. The content of the program is a mix of popular music and features (reportage, interviews, telegrams, gimmicks, etc.).

A typical weekly schedule starts on Fridays when the producer of the coming week and a reporter meet to establish an overview of next week's four programs. They spend 2-3 hours reading newspapers and magazines. They run through the suspension files into which everybody in the editorial unit puts ideas for a specific date. They read a list of upcoming events relevant for the channel. The list is produced and photocopied for all editorial units by a staff member. The list also reflects events and ideas promoted at the last editorial board meeting. They receive a list of news of general interest from external news agencies. Sometimes they order books from the library and tapes from an archive of earlier broadcasted material. They are informed by this week's producer of arrangements that are set up for the coming week. They finish by sketching potential features for the coming week.

At 8 o'clock, Monday through Thursday, a reporter starts running through the newspapers of the day and writes a list of headlines for the producer. He shows up at nine, turns on a computer with access to a news agency, NEWSSTAR. Since he finds the editor in NEWSSTAR as insufficient, the producer starts WORDPERFECT on another computer to make up the list of potential stories for the day. He looks into a paper file to see who is going to work on the day's program. Reflecting the concept of the radio program, he runs through the reporter's list, looking for stories that are adequate for montage, for the mobile recording unit, for mixing sound or music, and for inviting guests for telephone interviews. He prints out a list of about 20 potential stories for the day, makes photocopies and gathers the unit for a meeting to discuss which six or seven stories that the reporters will pursue. At 10 o'clock, back at the desk, the producer sorts out the list and takes print-outs for himself and the host, who is briefed when he shows up. During the day they both annotate the print-outs for individual purposes. He creates a new document rewriting the stories in the order he prefers. He takes into account which 
programs will be broadcasted before and after his program, and at what time guests can give interviews. The technicians show up to learn the schedule. The person operating the mobile recording unit calls to find out if, when, and where he is needed. The producer coordinates current status with the reporters to know if and how the stories will materialise or if new ones have to be researched. He checks with the editor responsible for daytime programs during the week to find out what other editorial units are working on. He keeps the schedule for the two studios. He, the assistant, and the host find the music for the program, taking the stories into account.

The reporters work on their stories. During the day reporters constantly check stories and angles with the producer and with each other, and they discuss the length of their feature to make them fit into the schedule of the program. For prerecorded broadcasting reporters use a tape recorder for interviews and for recordings of their own talk. They go to the studio where the material is edited for broadcasting assisted by a technician. They brief the host and deliver a tape to the producer, who makes a final check.

At 2 o'clock the producer, the host and the assistant (the group that works as a team during broadcasting) make up the final plan of the program including all features and music to be played. The assistant rewrites the plan on his computer adding minutes and seconds for each story and additional data for each music title, for the purpose of e.g. statistics and paying royalties. These processes finish close to deadline, and they are further stressed by reporters (coming and leaving) who have to check with the producer and to brief the host. The producer checks all prerecorded stories and sometimes he has to make cut-downs in order to make them fit the time schedule. The news group calls to coordinate, since every full hour the program is interrupted by the news. If the producer has a story that the news group has overlooked - or he wants them to overlook - he does not mention it, or he moves the story to before the news break. He makes a final check on NEWSSTAR for any big news before he leaves for the studio. During the entire process of producing the program the producer plays the role of a "center of coordination" (Suchman, in press). This gives the producer valuable information, while he considers some of the interactions as disturbances.

During the day the assistant is responsible for reporting on the day before's program. This involves collecting data from the reporters - data they were supposed to have delivered the day before. Furthermore he fills out forms for paying reporters' travels, artists whose music has been played, and experts who have given an opinion during the program.

During broadcasting the host is in a studio, while the producer, the technician, and the assistant are in an adjacent room. They can communicate by gestures through a big window, by microphones and loud speakers (the host has an ear piece), and they may meet, but only when the host is not on the air. They each have a paper copy of the final plan of the program, which they all individually 
annotate for personal use. The assistant notes the precise actual time and length of the broadcasted features and music titles (information needed for paying royalties). They each continuously update their copy of the plan when changes are made due to e.g. a prolonged live interview.

The description above of the previous work practices at Station $\mathrm{X}$ illustrates parts of our analysis at Channel 3. To sum up, we found the following areas as candidates for computer support for the entire channel:

- Coordination within and among editorial units. This type of coordination is a central part of the daily work mediated through meetings, phone calls and paper. Most employees interviewed found large parts of this coordination cumbersome. Also, management wanted enhanced coordination among all editorial units for the channel's profile to be perceived as more distinct, to avoid individual "kingdoms" of programs.

- Coordination between editorial units and the editorial board. This type of coordination was mediated mainly through the editorial board's weekly meetings, the editors responsible for a group of programs, and by the weekly paper list of upcoming events. Our analysis clarified that this type of coordination did not support management's request for a "forward planning process".

- The process of planning, production, broadcasting, and administrative follow up of the various elements that make up a radio program. Very early on during our observations we were led to believe that if the program elements, each consisting of one piece of music or one feature, were represented electronically, all data needed only be typed in and recorded once and could then easily be rearranged by the producer and accessed by several employees.

- Electronic access to material for research purposes. Observations and interviews highlighted a need for faster access to audio and written material.

- Digital recording, editing, and broadcasting. The planned shift from analogue to digital production and broadcasting would allow journalists to work on program elements in the same digital media from early planning until final broadcasting.

In the following, we focus especially on the first three candidates for computer support, addressing coordination within and among editorial units and between editorial units and the editorial board.

\section{Design for IT-use in Channel 3}

The results of the analysis in terms of problems, needs, and candidates for computer support were described and proposed in a report. It was presented to all employees at a hearing and to the steering committee and management of the channel. The purpose was to check the degree to which we had understood their work and to point out potential areas for IT-support. The users gave valuable 
feedback, which helped the steering committee to prioritise. After some minor changes we went further on to design, which comprised the following activities: Two visits abroad to radio stations using state of the art technology. This provided the design team with a shared reference for discussing and developing design ideas. Design workshops, where the design team collectively sketched future work practices on large sheets of paper. Sorting out design ideas, writing them down on stacks of post-it's and grouping them on a wall to provide an overview and to account for design ideas. And finally data modelling as a basis for the subsequent development of demonstration prototypes of all key design ideas.

These design activities caused the design team to revisit the result of the analysis to check or account for the design ideas. Also a couple of additional interviews had to be conducted to cover discovered holes in our understanding.

The design was presented to all employees at a hearing and to the steering committee and management of the channel. We demonstrated the prototypes and presented a report consisting of the analysis, a vision of the proposed suite of systems and their relations to the envisioned new work practices. The report also included a functional description of each system, a scenario of their future use, an evaluation of consequences for management and the employees, an implementation plan including organisational development and a required training program, and finally an economical estimate.

The overall design criteria has been to facilitate new types of coordination and to allow for qualitative improvements of work processes and of programs by providing easier access to existing and new research material and to reduce the time spent on routine tasks. In addition the design reflects major parts of the management's initiatives mentioned above. The design was proposed to be realised for the entire channel within 2 years. The employees were satisfied with the design, and management decided to purchase, develop, and implement the design.

In the presentation below we restrict ourselves to give only a very brief description of the proposed suite of systems, describing in some detail only two of the systems for the purpose of highlighting new ways of cooperation.

\section{The Overall Design}

In line with the business- and IT-strategy, we suggested a client/server solution with multimedia workstations connected to a LAN with access to the Internet. MiCROSOFT OFFICE was proposed since this was part of the corporation's IT-strategy too. The overall design consisted of fifteen systems. Two of these focused especially on coordination within and among editorial units and between these and the editorial board. They are in the following referred to as the Event Calendar and the Program Manager, and are described in further detail in the following. 


\section{The Event Calendar}

The Event Calendar satisfies a need for electronic access to research material and for coordination voiced during the analysis. It is maintained by a staff member, who creates and updates an electronic version accessible to everybody at the channel. It contains information that is mailed to him about concerts and CD releases, and e.g. political or musical events he finds in magazines and newspapers. It also reflects events and ideas promoted at the last editorial board meeting. He might indicate for which radio programs a certain event is relevant, and leave it to them to book events and indicate an angle on how they plan to cover the event. He may also indicate if he wants to be notified when an event is booked.

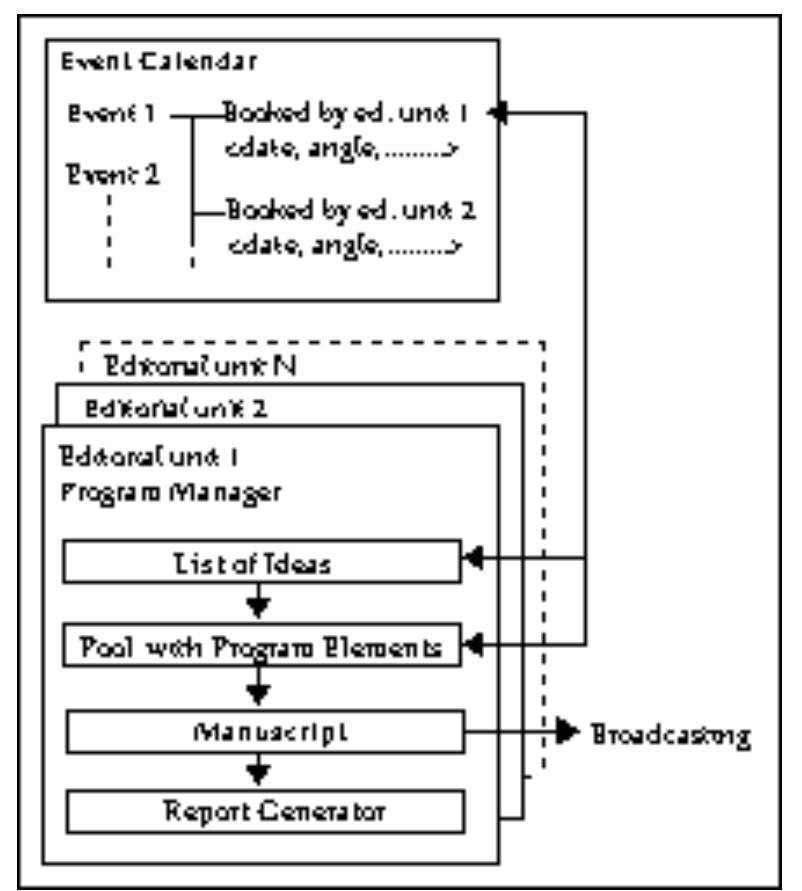

Figure 1. Illustration of the Event Calendar, the Program Manager, and the linking between them. Editorial units book events and indicate an angle. Data from the Event Calendar can be dragged to the List of Ideas in the Program Manager. Ideas evolve into Program Elements and are linked to the Manuscript, broadcasted and finally used by the Report Generator.

The Event Calendar also allows for the requested coordination among editorial units. Several editorial units might book the same event, but then they have to negotiate angles, thus preventing adjacent programs to bring the same stories. Data of an event (contact persons, date and time, type and genre, etc.) can be 'dragged and dropped' to the List of Ideas or a Program Element (see figure 1). By allowing for this type of coordination, the Event Calendar also works against the tendency voiced during the analysis, that each editorial unit thinks of its radio program being the channel instead of seeking to cooperate across programs. 
Finally the Event Calendar supports the editorial board in maintaining an overview for editorial purposes as it had requested. They might also decide that they want an event covered by a certain editorial unit. The system allows them to electronically notify the unit by putting an event into its List of Ideas - one way to obtain "visible management" as some employees had asked for.

In addition, since the events are linked to the List of Ideas and Program Elements (see figure 1) the editorial board may, if access is allowed, monitor the current status of features at all times until broadcasting (and even listen to prerecordings). This provides the technical means for supporting the "forward planning process."

\section{The Program Manager}

The Program Manager, which is linked to the Event Calendar, supports individual work as well as coordination between producer, host, reporters, technicians, and administrative staff in the editorial units. Seen from the perspective of an editorial unit such as Station $\mathrm{X}$, this is the central part of the design. The Program Manager is comprised of five elements:

- A List of Ideas. Each editorial unit has its own list where members of the editorial unit write general ideas and ideas for specific dates. Editorial units may suggest ideas to each others' lists of ideas also, and the editorial board may mark an idea as "mandatory".

- A Pool. This is the work space where journalists work on features for the day's program from "idea" to "ready for broadcasting". Ideas are dragged to the Pool where they are embodied in Program Elements (see below). All data about an idea is automatically inserted into specified fields in the Program Element. The Pool contains all Program Elements to be produced for the actual program.

- A Program Element gradually contains all data and sound for an element to be produced and broadcasted. A Program Element can be one of different types like feature, music (one title), jingle, spot, trailer, etc. Program elements are used to register both administrative, technical, and personal data (e.g. the script for the host). It holds a link to the sound file to be broadcasted if the Program Element is pre-recorded. The status of Program Elements may be inspected by the editorial board.

- The Manuscript is a template for the program where mandatory elements (e.g. the news every full hour, jingles, and spots advertising other programs) are present when initiated. Program elements from the Pool are linked to the Manuscript in the order decided by the producer. When the Program Element is linked to the Manuscript, the start/end times according to its current location in the Manuscript, and the (estimated or fixed) time for broadcasting the Program Element, are automatically calculated. The Manuscript gradually evolves from a plan for the program into the final version of Program Elements 
ready to broadcast. When the program starts the Manuscript is used directly from the studio for semiautomatic broadcasting.

- A Report Generator. Since all data, including a digital copy of the broadcasted program, are stored in the Manuscript, reports can be generated automatically.

The system allows an editorial unit to keep for themselves the content of a program until they choose to make it public (by using a "make public"-button), after which the editorial board and everybody else working at the channel may orient themselves into the plans of that editorial unit for the purpose of coordination.

The Program Manager saves the journalists a lot of multiple rewriting of information. It provides an editorial unit with a common overview of a program in progress. And it supports journalists in collecting - in one media - all the information relevant for themselves, the producer, the host, and the assistant. It saves the assistant a lot of time in gathering the various information needed for producing reports and for paying royalties. These are all requirements that stem from the analysis. In addition to such functional descriptions of the suggested systems, the design report holds a scenario of their use, data models, and an estimate of resources needed to develop and implement the design (see Kensing et al., forthcoming).

\section{Discussion}

We now turn to a discussion of the design, focusing on elements for supporting individual work, cooperative aspects, and the relation between technical features and organisational considerations. For this purpose, it is important to remember that the project was not about designing a single artefact, rather the design was a combination of organisational development and development of a suite of systems - some of which were purchased as standard systems while others were developed as customised systems. In the discussion we relate findings from the project to recent CSCW concepts: Computational coordination mechanisms as developed by Carstensen (1996), Schmidt and Bannon (1992), and Gerson and Star (1986); technologies of accountability as suggested by Suchman (1994); and Workflow from within and without as proposed by Bowers et al. (1995).

In an organisation such as Channel 3, constituted by a large number of cooperating ensembles of users, coordination is very complex. We have shown how it was based on various physical artefacts - and on human agents' social and professional skills. We suggested a distinction between coordination among editorial units, between editorial units and the editorial board, and within an editorial unit. 


\section{Coordination Mechanisms}

The Event Calendar and the Program Manager incorporate computational coordination mechanisms. They enable a dynamic program planning process - in two dimensions, vertical and horizontal.

\section{- Among Editorial Units}

Horizontal coordination among the editorial units was raised as a concern by journalists and management during the analysis. Therefore the Event Calendar was designed as a computational coordination mechanism which provides an overview of events and bookings. An editorial unit which tries to book an event is notified by the system if that event is already booked. Either it has to give up the event or it must negotiate angles with the one that booked first. The Event Calendar is also seen by management as a way of reducing "the small kingdoms" by promoting cooperation between the editorial units.

\section{- Between Editorial Units and the Editorial Board}

Vertical coordination addresses the relation between the editorial board and editorial units. Some journalists had asked for more "visible management" and the editorial board wanted to exercise "forward planning" instead of the previous "after broadcasting monitoring". Therefore the Event Calendar was designed as a computational coordination mechanism that enables the editorial board to promote or enforce ideas by changing dynamically the contents of the Event Calendar, instead of just updating the paper based version at the weekly meeting. On the other hand the Event Calendar and the Program Manager are tools by which the editorial units are able to dynamically inform the editorial board of the content of programs in progress - or the systems are "technologies of accountability" to use a term coined by Suchman (1994). However, during the analysis the design team became aware of a tension between on the one hand editorial units who want to work independently ("self steering groups" was also a management policy), while on the other hand they do acknowledge the editorial board's right to intervene. The questions were when and how editorial units need to account for their actions, and when and how it shall be possible for the editorial board to give orders/feedback on e.g. events covered, or whether or not the channel's music policy was followed. The design team raised this issue by implementing "make public-buttons" in the prototypes and by describing their use in the scenario of future use of the envisioned design. The degree to which the editorial board should be allowed access to plans was still discussed when we finished our design and thus left to the experiments during implementation and use. This reflects an understanding of design similar to Suchman's (in press): "... professional design needs to be understood not as an end point but as a starting place, or a platform, 
for the ongoing processes of "lay" design or design-in-use that are both inevitable and necessary for an effective working environment."

\section{- Within Editorial Units}

The Program Manager incorporates computational coordination mechanisms to be used within an editorial unit. It facilitates coordination in relation to planning and production of the program between the producer and the reporters, and among the reporters. And it eases the handing over of information from the journalists to the assistant as well as his production of reports. These features aim at the other sense of accountability - the ethnomethodological sense - that Suchman (1994) attributes to technologies. The reporters use the List of Ideas to store ideas for any member of the editorial unit as well as for other units to take up. The reporters store their ready made features in the Pool for the producer to link to his Manuscript. During broadcasting, the Manuscript facilitates coordination between the producer, the host, the assistant, and the technician. The coordination takes place partly via the Manuscript, partly via other coordination mechanisms (electronic communication, gestures, etc.). Thus this system addresses the predominant request for computer supported coordination raised by all editorial units during the analysis.

\section{Coordination Mechanisms in an Organisational Perspective}

\section{- Workflow from Within and Without}

Bowers et al. (1995) introduce an important distinction between workflow systems which reflect methods that are internal to the work (workflow from within) and systems which seek to order the work according to e.g. a general communication theory or a process model (workflow from without). Taking previous critiques of workflow systems (Orlikowski, 1992; Suchman, 1994; Bowers, 1995) into account, the Program Manager's workflow aspects were designed to mirror or reflect methods that the analysis showed were internal to the work. In addition we added new ways to access information for research purposes and new ways of coordination which the analysis showed were needed, but which the indigenous work practices did not support.

\section{- Linking of Mechanisms}

Gerson and Star (1986) denote coordination mechanisms as 'local and temporary closures'. Empirical studies by Carstensen (1996) suggest that coordination mechanisms might also have a more global character, functioning as a kind of workflow system that has evolved over time in a bottom up manner, that has grown out of practice, and he suggests that coordination mechanisms may also be linked - they may inter-operate. Our analysis of the work practice at Channel 3 clearly supports this. The producer's list of ideas that through many rewrites 
gradually evolved into a manuscript used by the team during broadcasting and by the assistant afterwards for the production of reports and for paying royalties was cumbersome and it often lead to breakdowns. Therefore the systems were designed to allow for coordination that goes beyond the previous paper based artefacts' ability to support coordination. The Event Calendar and the Program Manager each work as computational coordination mechanisms and they are linked (see figure 1). Since they are, or may be made, accessible to people outside the editorial unit, they enable new ways of coordination which the paper based coordination mechanisms did not allow for. It follows from the description above that the mechanisms are more than local and temporary closures in as much as they allow for more enduring and more extended kinds of closure, that reach beyond an editorial board, which the analysis of the previous work practice called for.

\section{- Dealing with conflicts}

The design of computational coordination mechanisms in an organisational context may entail conflicts. The editorial board wants to promote and enforce a "forward planning process" instead of "after broadcasting monitoring." On the other hand, the editorial units want to retain their autonomy - though they do acknowledge the editorial board's right to give suggestions and intervene, they still want to decide for themselves which events to cover and how.

To design computational coordination mechanisms and the linking of them are not just a matter of taking a set of technical criteria into consideration. It is also a question that resides in the realm of political discussions characterised by power, norms, and traditions for how such issues are dealt with in the organisation. What kind of computer support do we want - systems for control or for support, and support for whom? And who is the "we" who decides?

These issues have been dealt with in previous studies of CSCW-systems in use (see e.g. Bullen \& Bennett, 1990; Orlikowski, 1992; Okamura et al., 1994; Ackerman, 1994; Rogers, 1994). In most cases the product development oriented CSCW contributions have not taken organisational and political issues into account. However, design in a specific organisational context of coherent systems has to be organisationally feasible. This is why organisational issues have to be an integrated part of the design and implementation. We have demonstrated how technical and organisational issues can be dealt with during a project in an organisational context. The role of a design team is neither to cover up nor to solve political conflicts. Rather it should unveil such conflicts and help the parties to formulate technical and/or organisational ways of dealing with them, and leave it to them to solve the conflicts in the proper fora. During the project, organisational aspects were an integral part of our interactions with the management and employees of Channel 3. The project team's final report addressed such issues and evaluated the consequences for the various parties. 
Some controversies were solved as part of the evaluation of the report at the hearing and at the final steering committee meeting. Some were left to experiments and negotiations during the implementation.

\section{Channel 3 Conceived as Cooperating Ensembles}

Finally, what do we get from conceiving a complex organisation as cooperating ensembles of users when we design computer support for an organisation? The conception of Channel 3 as cooperating ensembles of users leads us to acknowledge the differences among the 25 editorial units and between these and the management. Some units are quite small and may eventually just comprise one person. Such persons are often "lonely riders" who don't fit into a group. They are allowed to work alone producing a weekly or biweekly program. Some units have very particular domains of interest, others are more general programs.

From this follows that there are differences in terms of work domain and workplace culture, and thus also differences in the perceived need for computer support, both in general and in terms of coordination in particular. Above we have focused on Station X, one of the larger editorial units. We expect the future use of computer support for individual work to be more or less identical among the editorial units. However, we expect the future work practice in relation to the coordination aspects of the systems to be quite diverse. This does not present a problem in relation to the design - as long as it is conceived of as consisting of a suite of systems. Individual users can choose which parts of the systems they want to use as long as a minimal set of reporting procedures, supported by the design, is followed.

The design facilitates improved managerial control of the content of programs. Though some conflicts were postponed to experiments and negotiations during development and implementation, the employees generally accepted the design because it also offered support for their individual and cooperative work.

To summarise, we have presented findings from a design project in an organisational context which involved detailed work practice studies of cooperating ensembles of users, and the participatory design of computer support for collaboration and individual work. Finally, these findings were discussed in terms of computational coordination mechanisms and related to politics at the organisational level.

\section{Acknowledgements}

We are very grateful for valuable comments by the anonymous reviewers and by Jeanette Blomberg, Susan Newman, Lucy Suchman, and Randy Trigg to a prior draft of the paper. Also we want to thank all the employees at Channel 3, the two designers, and their manager for a most valuable collaboration. 


\section{References}

Ackerman, M. S. (1994): "Augmenting the Organizational Memory: A Field Study Of Answer Garden", Proceedings of the Conference on Computer-Supported Cooperative Work,, ACM, New York, 1994, pp. 243-252.

Blomberg, J., J. Giacomi, A. Mosher, and P. Swendon-Wall (1993): "Ethnographic field methods and their relations to design", in Schuler, D. and A. Namioka (Eds.). Participatory Design: Perspectives on System Design, Lawrence Erlbaum, Hillsdale, NJ, 1993, pp. 123-154.

Blomberg, J., L. Suchman, and R. Trigg (1996): "Reflections on a Work-Oriented Design Project", in Human-Computer Interaction, Vol. 11, 1996, pp. 237-265.

Bowers, J., G. Button, and W. Sharrock (1995): "Workflow from Within and Without", in H. Marmolin, Y. Sundblad, and K. Schmidt (Eds.), Proceedings of the Fourth European Conference on Computer Supported Cooperative Work, Kluwer, Dordrecht, 1995, pp. 51-66.

Bullen, C. V. and J. L. Bennett (1990): "Learning from User Experience with Groupware", Proceedings of the Conference on Computer-Supported Cooperative Work, ACM, New York, 1990, pp. 291-302.

Carstensen, P. (1996): Computer Supported Coordination, Ph.D. Thesis, Department of Computer Science, Roskilde University.

Gerson, E. M., and S. L. Star (1986): "Analyzing Due Process in the Workplace", Transactions on Information Systems, Vol. 4, No. 3 July 1986, pp. 257-270.

Greenbaum, J. and M. Kyng (Eds) (1991): Design at Work: Cooperative Design of Computer Systems. Lawrence Erlbaum Associates, Chichester, UK.

Grudin, J. (1991): "Interactive Systems Bridging the Gaps between Developers and Users", IEEE Computer, April, 1991, pp. 59-69.

Hughes, J. A., D. Randall, and D. Shapiro (1992): "Faltering from Ethnography to Design", Proceedings of the Conference on Computer Supported Cooperative Work, ACM, New York, 1992, pp. 115-122

Hughes, J. A., D. Randall, and D. Shapiro (1993): "From Ethnographic record to System Design: Some Experiences From the Field", in Computer Supported Cooperative Work (CSCW): An International Journal, Vol. 1, No. 3, Kluwer, Dordrecht, 1993, pp. 123-141

Kensing, F. and T. Winograd (1991): "Operationalizing the Language/Action Approach to Design of Computer-Support for Cooperative Work". In R. K. Stamper et al. (Eds.) Collaborative Work, Social Communications and Information Systems, North-Holland, 1991, pp. 311-331.

Kensing, F, J. Simonsen, and K. Bødker (1996): "MUST - A Method for Participatory Design", in Blomberg et al. (Eds.), PDC'96: Proceedings of the Participatory Design Conference, CPSR, Palo Alto, 1996, pp. 129-140.

Kensing, F, J. Simonsen, and K. Bødker (forthcoming): "Participatory Design at a Radio Station", submitted to Computer Supported Cooperative Work (CSCW): An International Journal, Kluwer, Dordrecht.

Mogensen, P and D. Shapiro: "When Survival is an Issue: PD in support of landscape architecture", in Blomberg et al. (Eds.), PDC'96: Proceedings of the Participatory Design Conference, CPSR, Palo Alto, 1996, pp. 55-62.

Muller, M. J., and S. Kuhn (1993) : "Participatory Design. Introduction", in Communications of the ACM, June 1993, Vol. 36, No. 4, pp. 24-28

Okamura, K., M. Fujimoto, W. J. Orlikowski, and J. Yates (1994): "Helping CSCW Applications Succeed: The Role of Mediators in the Context of Use", Proceedings of the Conference on Computer-Supported Cooperative Work, ACM, New York, 1994, pp. 55-65. 
Orlikowski, W. J. (1992): "Learning from Notes: Organizational Issues in Groupware Implementation", Proceedings of the Conference on Computer-Supported Cooperative Work, ACM, New York, 1992, pp. 362-369.

Plowman, L., Y. Rogers, and M. Ramage (1995): "What Are Workplace Studies For?", in H. Marmolin, Y. Sundblad, and K. Schmidt (Eds.), Proceedings of the Fourth European Conference on Computer Supported Cooperative Work, Kluwer, Dordrecht, 1995, pp.309-324.

Rogers, Y. (1994): "Exploring Obstacles: Integrating CSCW in Evolving Organisations", Proceedings of the Conference on Computer-Supported Cooperative Work,, ACM, New York, 1994, pp. 67-77

Schmidt, K. and L. Bannon (1992): "Taking CSCW Seriously: Supporting Articulation Work", Computer Supported Cooperative Work (CSCW): An International Journal, Vol. 1, Nos. 1-2, Kluwer, Dordrecht, The Netherlands, 1994, pp. 7-40.

Suchman, L. (1994): "Do Categories Have Politics? The language/action perspective reconsidered", Computer Supported Cooperative Work CSCW): An International Journal, Vol. 2, No. 3, Kluwer, Dordrecht, The Netherlands, 1992, pp. 177-190.

Suchman L. (in press): "Centers of Coordination: A case and some themes". To appear in L. Resnick, R. Saljo, and C. Pontecorvo (eds.) Discourse, Tools, and Reasoning. Springer-Verlag, in press. 